\title{
Correspondence
}

Br Heart F 1981; 46: 222-3

\section{Incidence of coronary artery disease in patients with valvular heart disease}

Sir,

We read the paper by Morrison et al. ${ }^{1}$ with interest.

In a larger study of 643 patients with valvular disease, we have also shown that significant coronary disease is not an uncommon finding in patients without angina. ${ }^{23}$ However, in contrast to Morrison et al., who could find "no adequate clinical markers for such coronary lesions", we found that the incidence of significant coronary disease was directly related to the number of coronary risk factors present. More recently we have analysed a prospective study involving 387 patients with valvular disease and again shown a direct association between coronary disease and the number of coronary risk factors.

In April 1980, we presented our retrospective data, showing the association between coronary artery disease, angina, and coronary risk factors. ${ }^{2}$ We stressed that the incidence of coronary artery disease in those patients without both angina and risk factors was extremely low and suggested that preoperative coronary arteriography might be omitted in this group. The risk factors examined included hypertension, cigarette smoking (more than 10 cigarettes a day for 10 years), family history of ischaemic heart disease, overweight, hyperlipidaemia, and hyperglycaemia. More recently we have performed logistic regression analysis on these data and are now examining the strength of these findings by a similar analysis of the more comprehensive prospective data.

The failure by Morrison and his co-workers to detect important clinical markers of coronary disease is because of their omission to study the accepted risk factors for coronary artery disease. Age alone appeared to be the only consistent, positive correlate and, not surprisingly, left ventricular end-diastolic pressure, ejection fraction, pulmonary artery pressure, and cardiothoracic ratio were unhelpful. It is also unclear from their paper whether or not a history of myocardial infarction or electrocardiographic evidence of infarction were actually included in their analysis and it is not apparent what constituted a positive smoking history in terms of cigarette consumption.

Our results from studying over 1000 patients indicate that the incidence of coronary artery disease is related to the number of associated coronary risk factors (as defined above) and that routine coronary arteriography might be omitted in a substantial proportion of patients in whom both angina and risk factors are absent.

D R Ramsdale,
D H Bennett,
C L Bray,
E B Faragher,
Regional Cardiac Centre,
Wythenshawe Hospital,
Manchester M23 9LT.

\section{References}

1 Morrison GW, Thomas RD, Grimmer SFM, Silverton PN, Smith DR. Incidence of coronary artery disease in patients with valvular heart disease. $\mathrm{Br}$ Heart $\mathcal{F}$ $1980 ; 44: 630-7$.

2 Ramsdale DR, Bennett DH, Bray CL, Ward C, Beton DC, Faragher EB. Yield of coronary arteriography in patients before valve replacement (abstract). $\mathrm{Br}$ Heart $\mathcal{F}$ 1980; 43: 721.

3 Ramsdale DR, Bennett DH, Bray CL, Ward C, Beton DC, Faragher EB. Coronary arteriography prior to valve replacement. Eur Heart f 1981; 2: 83-6.

This letter was shown to Dr Morrison and his coauthors who reply as follows:

Sir,

Of our 239 patients, 12 had a history of myocardial infarction, 10 being left with residual angina. We studied the electrocardiograms of all patients but found that the effects of ventricular hypertrophy and treatment with digitalis prevented confident identification of ischaemic change. A positive smoking history was at least 10 cigarettes daily for 10 years including a small number who had stopped within five years of investigation.

Identification of risk factors is a logical extension of our approach and the results published by Ramsdale $e t$ $a l$. are impressive. ${ }^{\prime}$ We were, however, worried that their criteria for risk may not have been stringent 
enough (for example hypertension exceeding only $150 / 90 \mathrm{mmHg}$, and family history including aunts, uncles, and grandparents). We therefore reviewed our data to determine how many of our patients were completely free from risk factors. The exclusions were made in the following order: there was information available from 234 patients of whom 125 had no chest pain; 57 of these were non-smokers of whom 42 had no family history of ischaemic heart disease; 35 of these had normal fasting serum lipids of whom 32 had no diabetes mellitus or overweight. Therefore, only 32 (14\%) of our patients had no risk factors and, furthermore, five ( $16 \%)$ of these had significant coronary artery disease.

Thus, in only a minority of patients may coronary arteriography be omitted by virtue of the absence of the risk factors postulated by Ramsdale $e t$ al. and these may still have a sizeable incidence of coronary artery disease.

GW Morrison,

R D Thomas,

S F M Grimmer,

P N Silverton,

D R Smith

Department of Cardiology, The General Infirmary, Leeds.

\section{Reference}

1 Ramsdale DR, Bennett DH, Bray CL, Ward C, Beton DC, Faragher EB. Coronary arteriography prior to valve replacement. Eur Heart $\mathcal{F}$ 1981; 2: 83-6. 